\title{
THE STUDY OF CHANGES IN ARDABIL PLAIN GROUNDWATER LEVEL USING GIS
}

\author{
Javad Zare Aghbolagh ${ }^{1}$, Ebrahim Fataei ${ }^{1, *}$ \\ 1 Department of Environment, Ardabil Branch, Islamic Azad University, Ardabil, Iran, e-mail: zare.javad66@ \\ gmail.com \\ * Corresponding author e-mail: ebfataei@gmail.com
}

Received: 2015.12.15

Accepted: 2016.02.01

Published: 2016.03.01

\begin{abstract}
Uncontrolled exploitation of groundwater in many parts of the world has led to a sharp drop in groundwater levels. In this study, changes in Ardabil plain groundwater level were studied using geographic information system (GIS). For this purpose, the interpolation table method was used, the intrinsic data as table data of piezo metric wells was used. In order to implement the model, the Majol Geoestatical in geographic information system software was used. The data entered as regions into the geographic information system, and then done for the entire zoning area, due to zoning 8 models, the IDW, GPI, $\mathrm{RBF}, \mathrm{LPI}, \mathrm{KO}, \mathrm{KS}, \mathrm{KU}$ and EBK in geostatical extension were evaluated. The ordinary kriging method $(\mathrm{KO})$ with the lowest RMSE, was determined as the most accurate one, and finally, as the ultimate method for zoning and map providing for the changes in groundwater levels drop of the region. The results of classification showed that the biggest drop of about 40 meters was in the areas close to the southeastern parts of the study region and in other areas, little changes were observed, this rate of the change and decline in some parts of the desert like southern regions is very tangible and specified.
\end{abstract}

Keywords: Ardebil plain, groundwater, GIS, interpolated.

\section{INTRODUCTION}

The provided statistics by the world resources illustrate a dilemma in the trend of annual drop in the ground water. The deficit in volume of the global groundwater storage annually is between 700 to 800 billion cubic meters, out of which $1 \%$ belongs to Iran $[1,10]$. In some countries with dry areas in which, the underground water has been used more than the consumption amount, and with full discharging of it, they are facing severe difficulties in the supply of water at the moment $[11,13]$ so being aware of the status of water resources both in terms of quality and quantity is the most important implementation to prevent the destruction of water resources [4]. Within the recent years in Ardabil desert uncontrolled exploitation has caused a significant drop in groundwater resources that land subsidence in some areas of the plain especially in southern parts is one of its reasons [2]. Shafi'I Motlagh (1388) stated that the risk of water resources crisis, which is caused by a sharp decline in precipitation and wrong methods of irrigation and uncontrolled exploitation of groundwater resources draws a troubling future ahead of us. Akbari et al. (1388) conducted research to assess the groundwater levels drop of Mashhad plain, the statistics of 70 observed wells during 2 periods of 10 years (76 in 1366 and 87 in 1377) examined, and the results showed that during 20 years, the rate of $1.12 \mathrm{~m}$, and it means that averagely every year $60 \mathrm{~cm}$ water level has been reduced.

The GIS is one of the most practical knowledge, in addition, high profitability, accelerates the process of work, i.e. planning, and determining critical activities [14]. The ability of this system in management, planning and strong statistical analysis has made many people in different fields use it as a powerful tool in making deci- 
sions [8]. Ebrahimi et. al. (2009) by evaluating the effect of drought on wetland water surface of Chaharmahal and Bakhtiari province utilizing the GIS and remote sensing technology made this conclusion that by the means of uncontrolled exploitation of groundwater and effects of drought, the Pond water surface also decreased. Albertson and Henington (1995) reviewed the analysis of groundwater resources by using GIS. Makoto et. al. (2008) conducted a research in an area of evergreen forest in the central Cambodia river basin, and measured groundwater level fluctuations and analyzed the movement of groundwater using boundary conditions and parameters that in field operations were able to be measured. The results showed that, generally in the rainy season the height of groundwater level increases and in the dry season drops $[9,12]$. In this study, decline in groundwater levels in the Ardebil plain aquifer using interpolation functions and zoning in the GIS was conducted, due to high population density, limited water resources in groundwater and removal of surplus capacity, increasing the acreage surface of crops, decline in groundwater levels and land subsidence.

\section{MATERIALS AND METHODS}

Study region: Ardabil plain in the eastern part of Azerbaijan plateau and in terms of the country divisions is located in the center of Ardabil province. The total water resources of Ardabil county are around 95/285 million cubic meters embody 120 million cubic meters surface water and groundwater 95/165 million cubic meters (recoverable from wells and subterranean). The volume of mentioned groundwater in the city of Ardabil through 39 series of aqueducts (85/1 million cubic meters) and 2192 wells (3/126 million cubic meters) utterly 15/128 million cubic meters are currently used (Ardabil Regional Water Company, 1392). illustrates the Ardebil plain position in Iran and Ardebil city (Figure 1).

In order to do the following research, the statistics of 56 peso metric wells within the watery years 1350 to 1393 were used. After sorting the resulted data in Microsoft Excel environment, the column chart of the studied time period was drawn. The aim of drawing the following chart was the overview of underground water variation trends. Application used in this research,

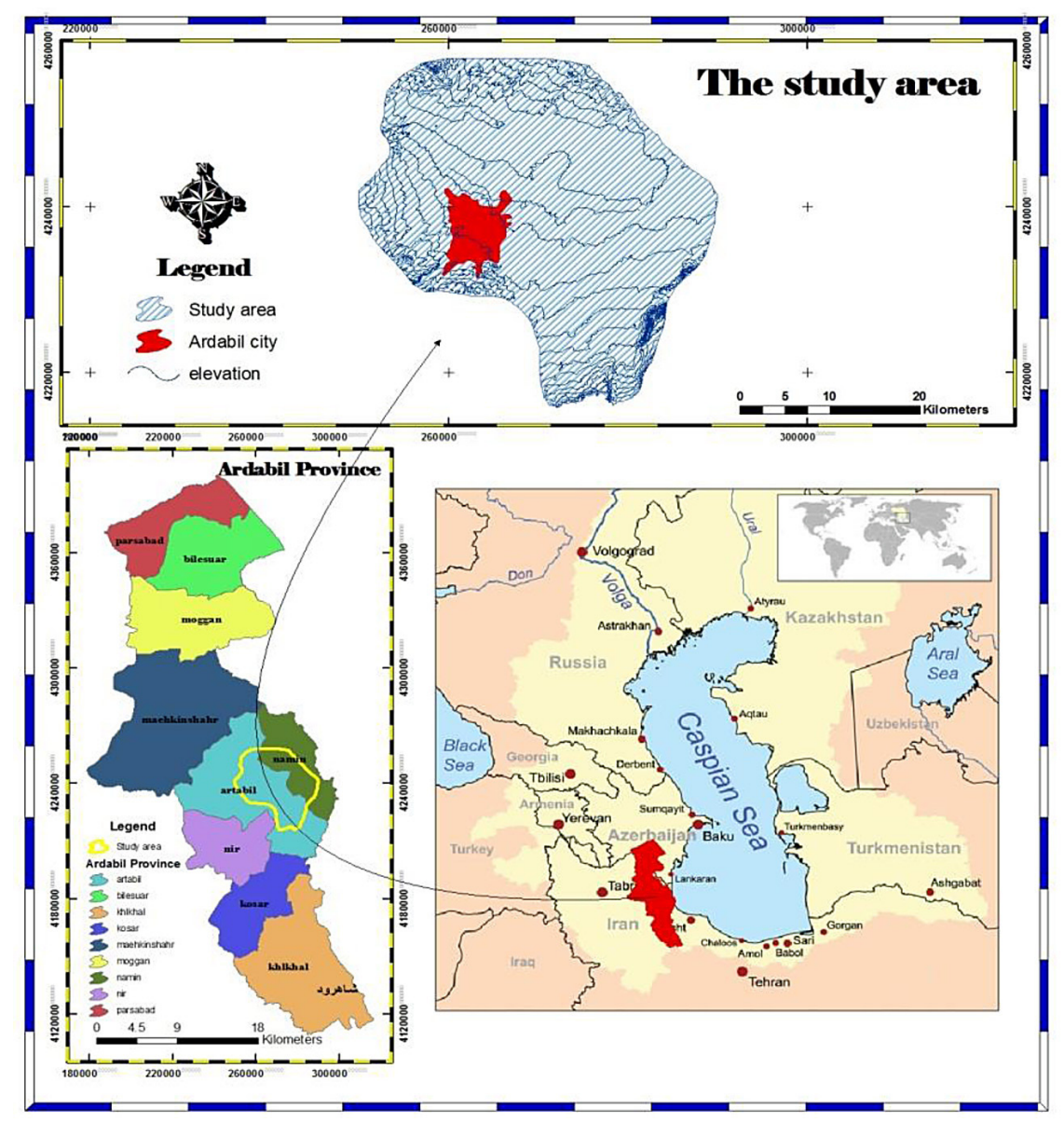

Fig. 1. the condition of study region in Ardabil province and Iran 
was ARC GIS software, version 2.10. In this study, due to providing the final map for drop in the groundwater levels, associated information to wells in the whole area was extended, that's why the interpolation model was used to examine the final map. According to this status that claims how the resulted data related to the rate of RMSE is lower, it illustrates this interpolation model as the efficient model for exhibiting the related information to peso metric wells in the total region. 8 models including Inverse distance weighting, Global polynomial interpolation, Radial basis function, local polynomial interpolation, kriging - ordinary, kriging - simple, kriging - universal, Empirical Bayesian kriging were studied. For the implementation of model in geographic information system software, the Majol Geostatical model was used.

\section{RESULTS AND DISCUSSION}

Throughout the Ardabil plain an unconfined aquifer extends across it. Because of the uneven stone floor and existence of the feeding areas of surrounding mountains, the aquifer is not homogeneous and does not have the same situation in terms of watering. According to Figure 2, it is clear that Piraqum village near the southeastern of the area with about 40.38 meters of drop within the years 1961-1993 has the heighest exploitation and relevance to villages such as Nouran, Jabe dar lands, Aghcheh Kandy, Yajlu, Saadi Street, Niyar and Saeed Abad, in the northern half of the area with the loss of about $0 \mathrm{~m}$ and by the years 1961-1993 have the lowest uptake shown in Figure 2.

\section{INTERPOLATION DATA}

Figures 3 to 10 illustrate the relevant information to the unknown regions prediction and the related error in determination of these parts for the used 8 models.

The measurement of validation results showed that the ordinary kriging method with the lowest RMSE (Table 1) is the most accurate one, and finally was selected as the ultimate method for preparing the map changes in groundwater level decline of the region.

The zoning map of changes in groundwater level drop in the entire plain was developed using ArcGIS software (Figure 11).

The zoning maps and distribution of wells show that the highest values of changes and the amount of ground water level reduction are in the southeast and in the villages (Khalil Abad, Merny, Piraqum and big Arallo).

Based on the circumstances and characteristics of Ardabil plain, there is a free aquifer that is extended throughout the Ardabil desert in which

Table 1. The RMS rate and average for each methods of interpolation

\begin{tabular}{|l|c|c|}
\hline \multicolumn{1}{|c|}{ Method } & Mean & RMSE \\
\hline Inverse distance weighting & $-0 / 39$ & 8.185463 \\
\hline Global polynomial interpolation & $0 / 06716$ & 10.36717 \\
\hline Radial basis function & $-0 / 32$ & 7.6060 \\
\hline local polynomial interpolation & $-0 / 6153$ & 7.7790 \\
\hline Kriging - ordinary & $-0 / 1895$ & 7.4861 \\
\hline Kriging - simple & $0 / 06$ & 8.5684 \\
\hline Kriging - universal & $-0 / 1895$ & 7.7861 \\
\hline Empirical Bayesian kriging & $-0 / 01757$ & 7.6417 \\
\hline
\end{tabular}

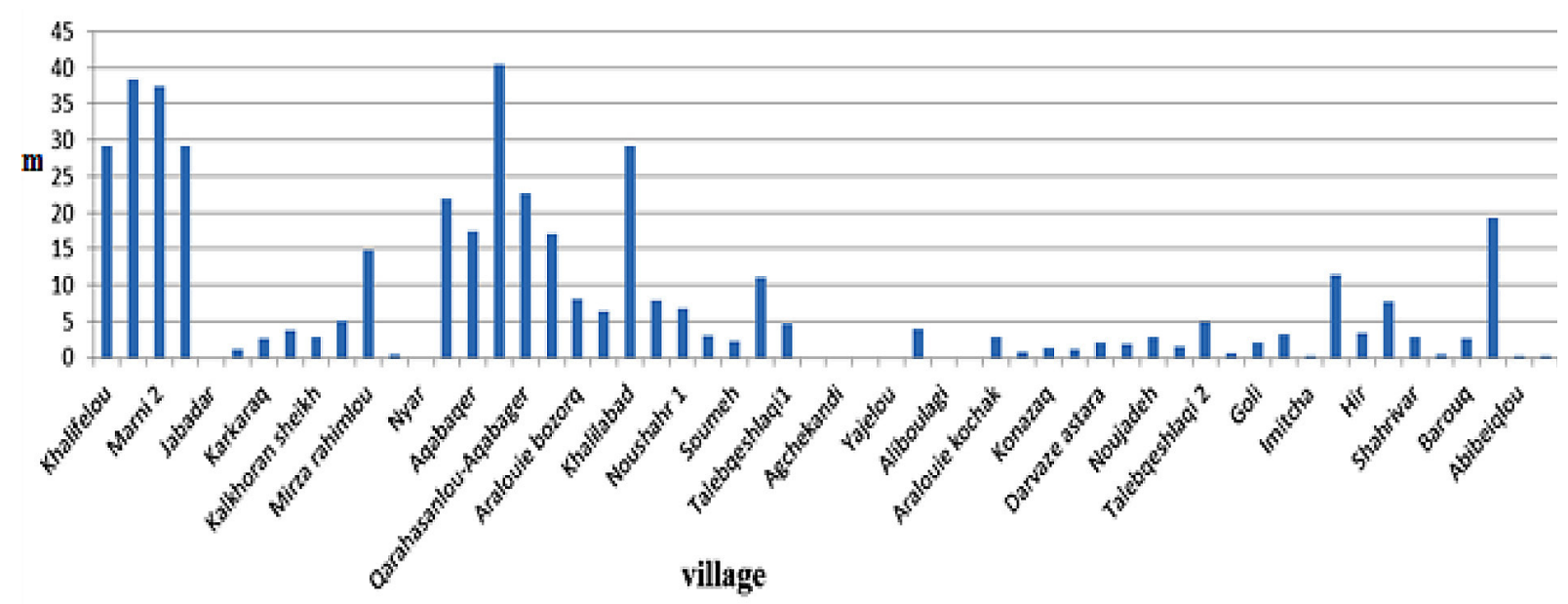

Fig. 2. The changing rate of groundwater decline in the wells of Ardabil plain villages 

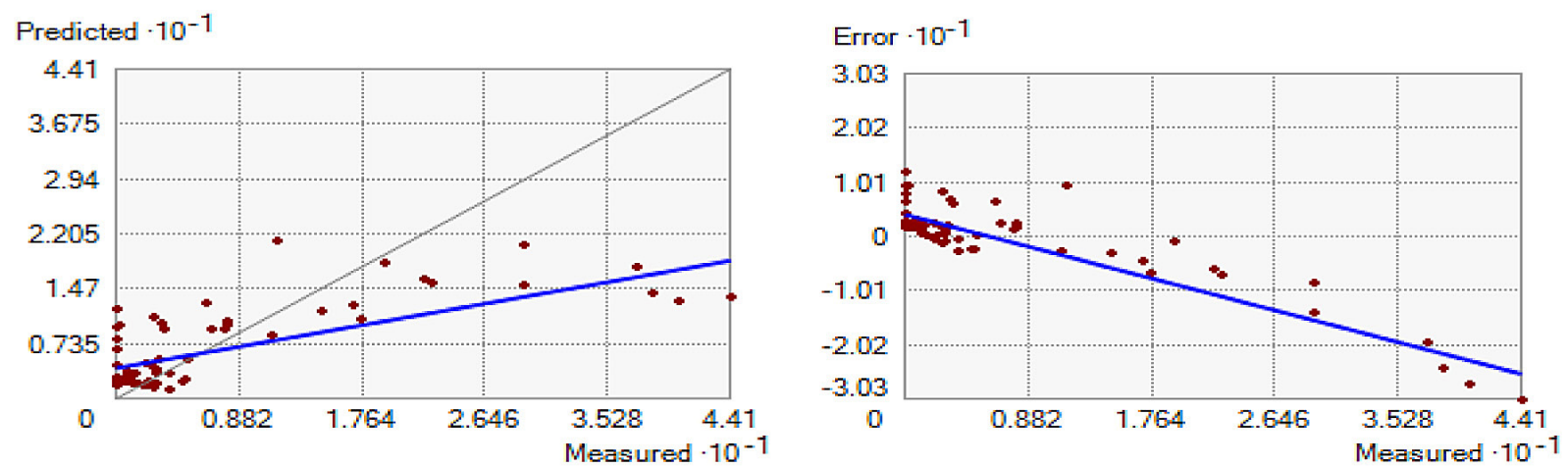

Fig. 3. The error chart and prediction for the Inverse distance weighting model
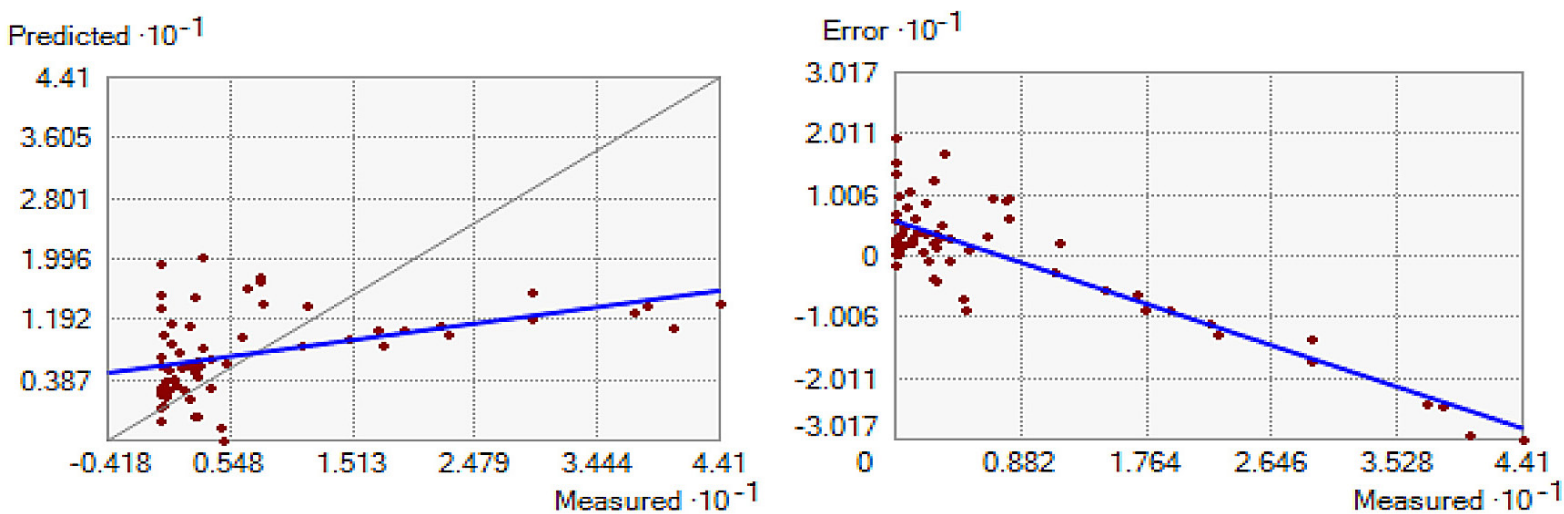

Fig. 4. The error chart and prediction for the Global polynomial interpolation model

Predicted $10^{-1}$

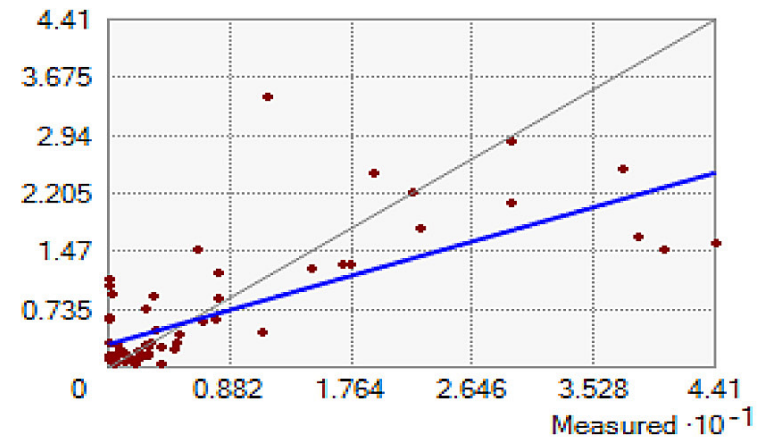

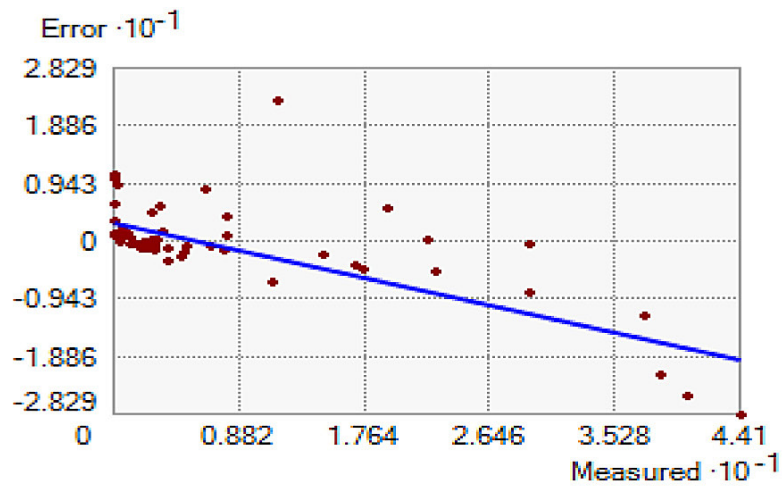

Fig. 5. The error chart and prediction for the Radial basis function model
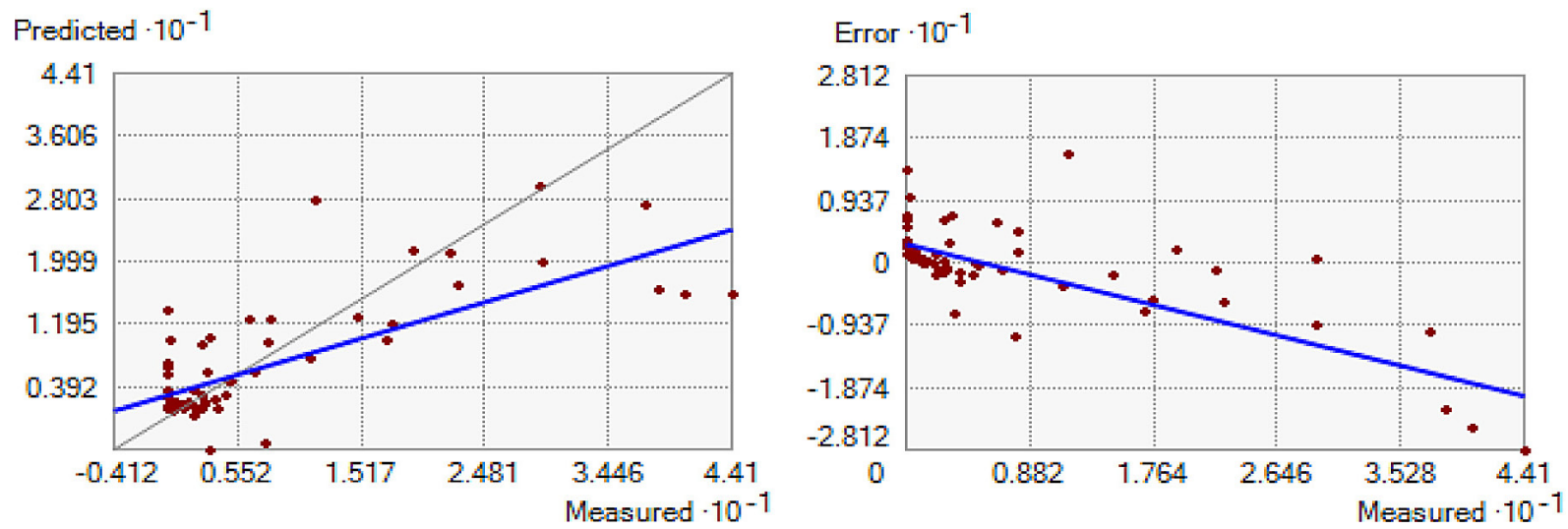

Fig. 6. The error chart and prediction for the local polynomial interpolation model 

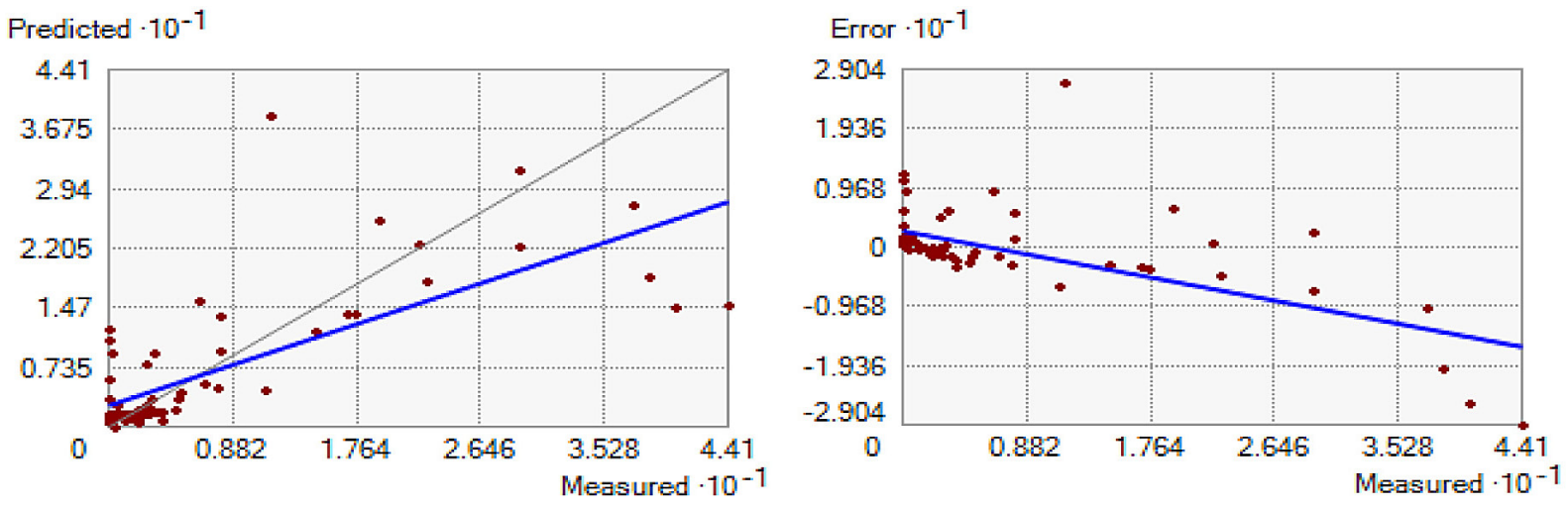

Fig. 7. The error chart and prediction for the kriging - ordinary model
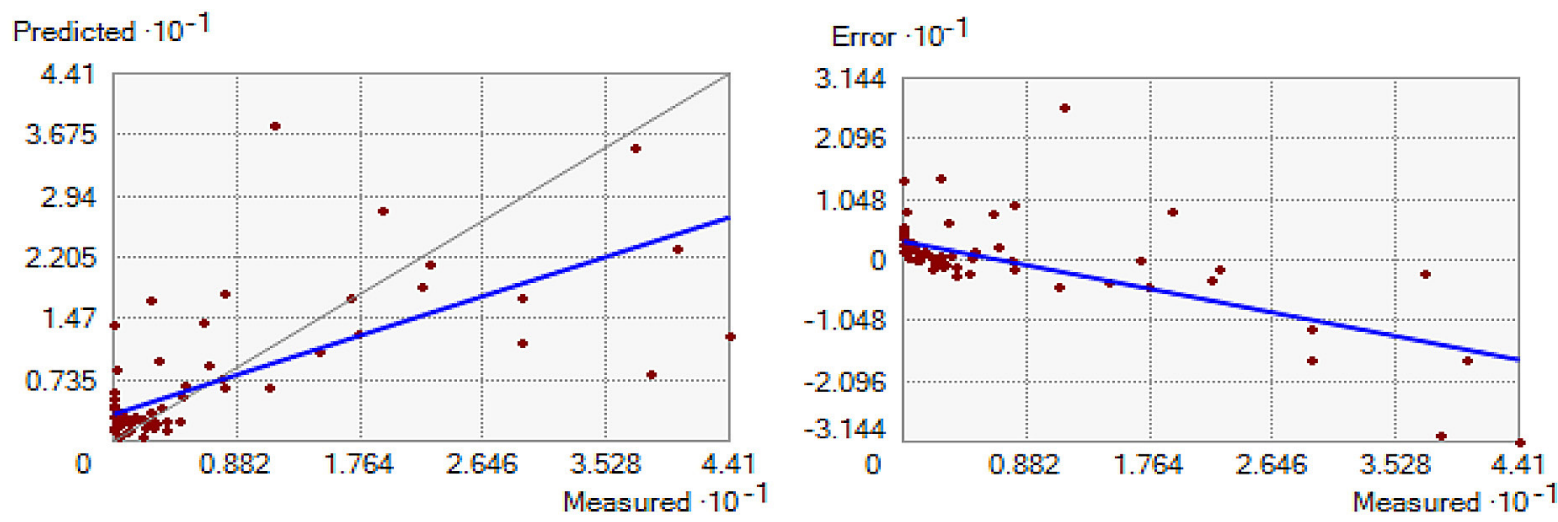

Fig. 8. The error chart and prediction for the kriging - simple model
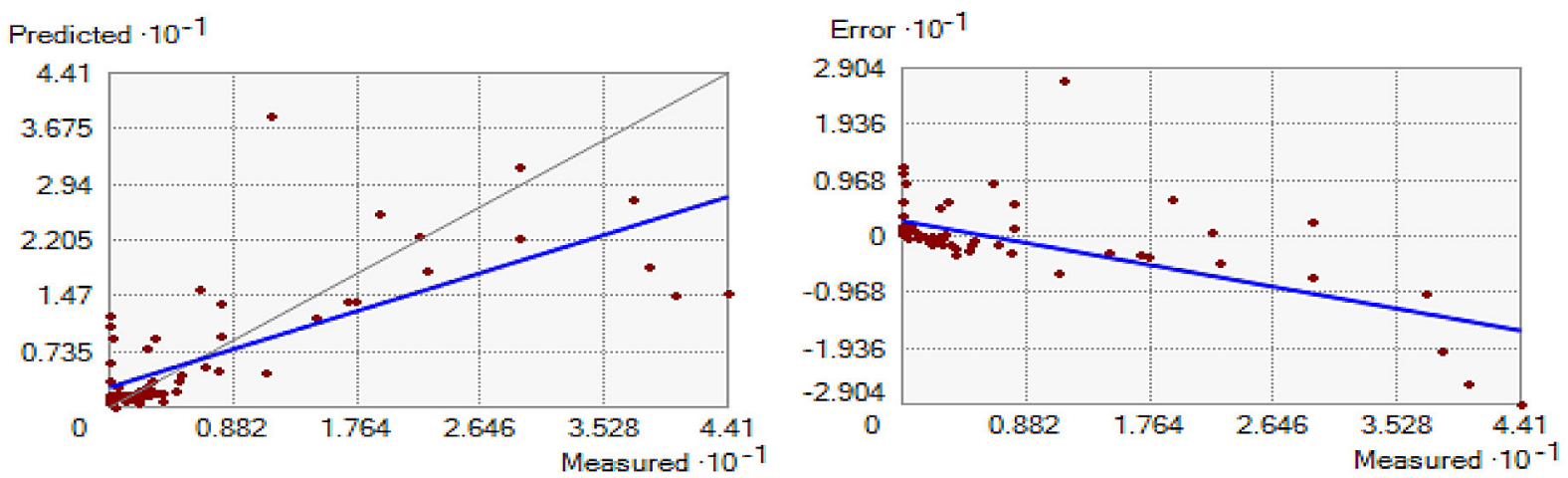

Fig. 9. The error chart and prediction for the kriging - universal model
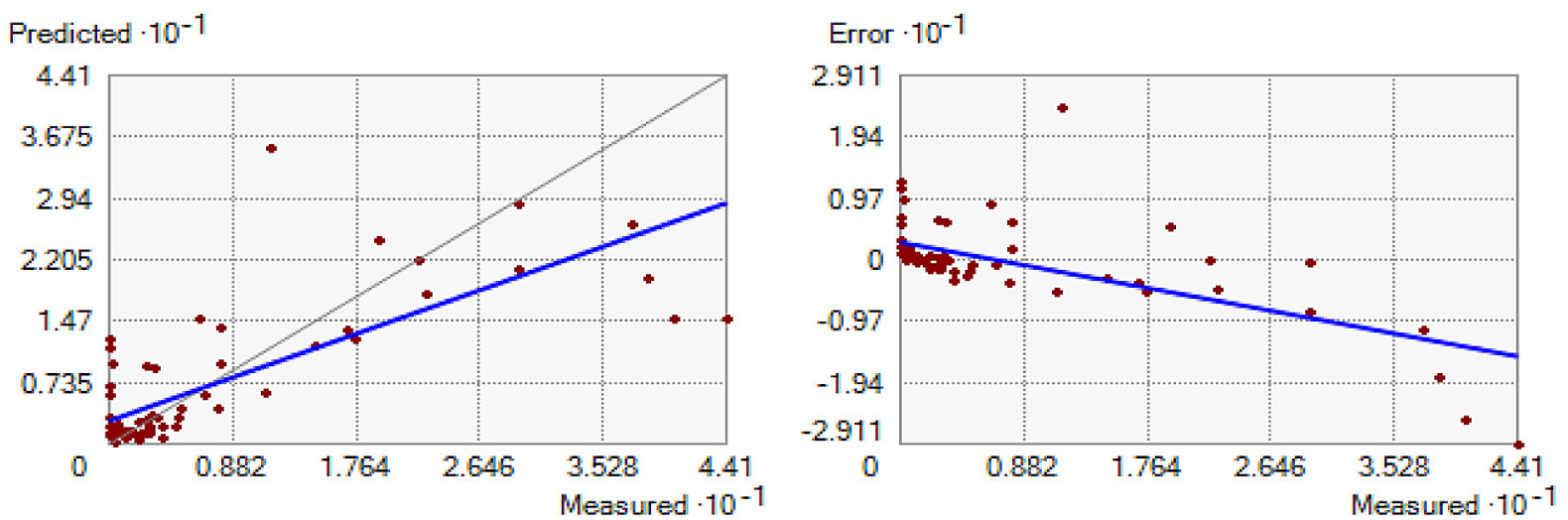

Fig. 10. The error chart and prediction for the empirical Bayesian kriging model 


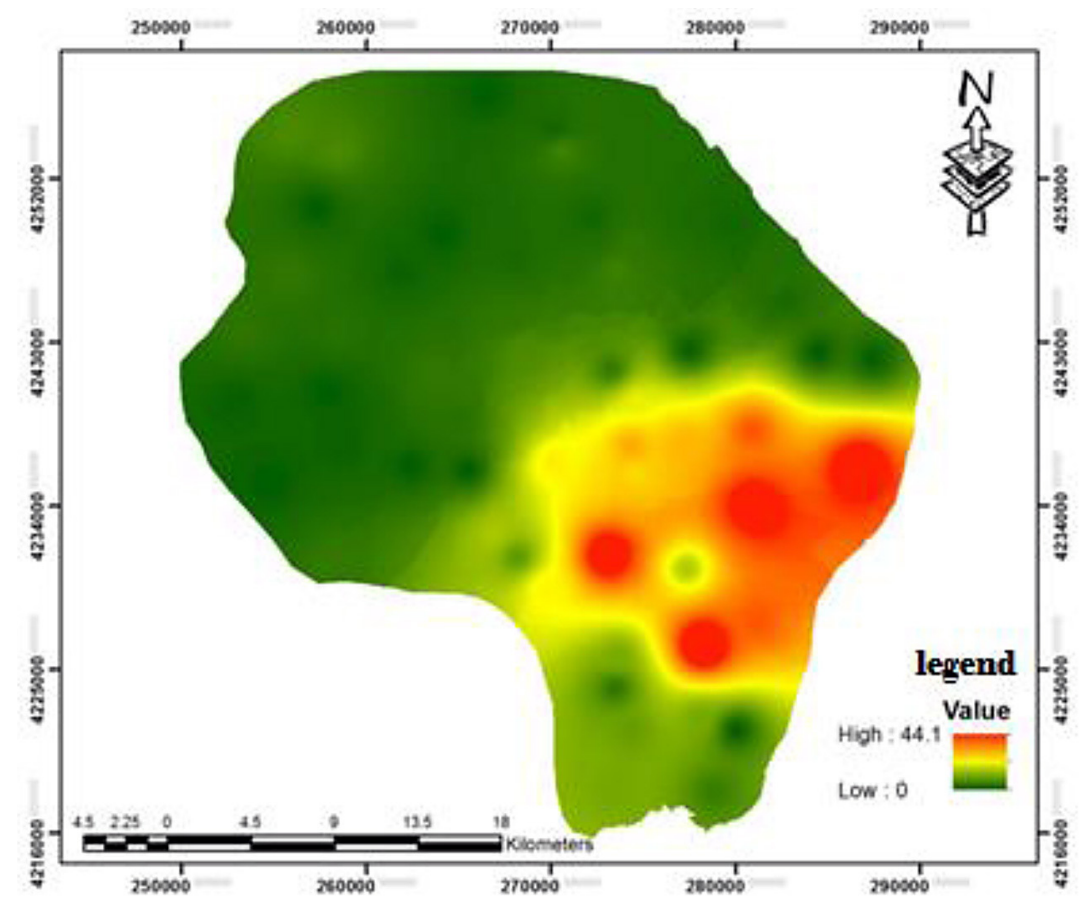

Fig. 11. The changes of groundwater drop table in Ardabil plain

this aquifer has broaden in the middle of the fertile lands and settlement of the studied wells in the agricultural fertile regions and uncontrolled exploitation from the aquifers in the recent years have caused a sharp fall in the water of these areas. Akbari et al. [1] also studied the groundwater level drop in Mashhad plain, and came to this conclusion that ground water levels in the central and western parts of the aquifer was reduced to 30 meters. The focus of the harvest wells with high flow rates in the region has caused this phenomenon.

\section{CONCLUSIONS}

In the past, irregular and incorrect exploitations of groundwater caused a drop in groundwater levels and in some cases, caused the groundwater aquifers to be dried in some parts of the country. Population growth, technology progress and other factors caused excessive water withdrawals for different uses such as drinking, industry and agriculture in different regions. In this context, due to withdrawing too much water for agriculture is the main factor that could make a significant decrease in the level of groundwater table. In the Ardebil plain during recent years due to excessive harvest about 500 million cubic meters of water have declined from the reservoirs. This rate of changes and reduction in some ar- eas of the desert, such as southern regions are very tangible and specific. This information as regions is entered into the geographic information system, and then done to all zoning areas. For zoning, 8 models including: IDW (Inverse distance weighting), GPI (global polynomial interpolation), RBF (radial basis furction), LPI (local polynomial interpolation), KO (kriging ordinary), KS (kriging - simple), KU (kriging - universal) and EBK (empirical Bayesian kriging) in geostatical extension were studied and two models with the lowest RMSE were finally accepted and eventually based on the ordinary kriging model. The unknown regions for the entire area was zoned. The results showed that the highest drop with about $40 \mathrm{~m}$ was in the areas close to the southeast of the study area and in other areas, little change was observed. Accordingly, we can say, the density of population and much exploitation of groundwater for agriculture, industry and drinking water caused a sharp drop in these regions.

\section{REFERENCES}

1. Akbari M., Jorge M.R., Madanisadat H., Evaluation of underground water level drop using Geographic Information System (GIS). Case Study: Mashhad Plain Aquifer. Journal of Soil and Water Conservation Research, 44(4), 2009, 144-156. 
2. Razavian M.T., Ghafori Poor A., Razavian M., Green roofs. Journal of the Preparation, 2010; 215-226.

3. Shafiee Motlagh K.H., Evaluation of a sharp drop in the underground water in the province with special attention to the sliding clutch of plain kohkiloye and Boyer ahmad. Global Water Conference, Islamic Azad University, Behbahan, 2009, 67-81.

4. Keshavarzi H.A., Bashiri M., Ojaghlo A., Factors affecting spatial and temporal variations in groundwater salinity and depth. Case study: Ghorveh. First National Conference on the Challenges of Water Resources and Agriculture, Islamic Azad University, Khorasan. 2012, 195-213.

5. Albertson P.E. Hennington G.W., Groundwater analysis using a geographic information system following finit-differenced and element techniques. Engineering Geology, 42, 1995, 167-173.

6. Makoto A., Akira S., Naoki K., Tatsuhiko N., Eriko I., Yasuhiro O., Koji T., Jumpei T., Bora T., Sopheavuth P., Sopheap L. ,Saret K., Seasonal fluctuation of groundwater in an evergreen forest, central Cambodia: Experiments and two-dimensional numerical analysis. Paddy and Water Environment Journal, 6(1), 2008, 37-46.

7. Ebrahimi A.A., Mohammadi F., Kaveh N., Malekmohamadi M. 2009. Effect of drought on wetlands using RS and GIS. In: The 5th Conference on Watershed Management (Natural Hazards Sustainable Management). Gorgan, Golestan, Iran.
8. Makhdoum A.F., Darvishsefat A.A., Jafarzadeh H.H., Environmental evaluation and planning by geographic information system. Tehran Univ. Press, 2002, pp. 304.

9. Walker W.R., Hrezo M.S., and Haley C.J., Management of water resources for drought condition. National Water Summery. Geological Survey Water Supply, Paper No. 2375, 1991, 147-156.

10. Tremblay L., Larocque M., Anctil F., Rivard C., Teleconnections and interannual variability in $\mathrm{Ca}$ nadian groundwater levels. Journal of Hydrology, 410, 2011, 178-188.

11. Grasby S.E., Chen Z., Hamblin A.P., Wozniac P.R.J., Sweet A. Regional characterization of the Paskapoo Bedrock Aquifer System, southern Alberta. Can. J. Earth Sci. 45(12), 2009, 1501-1516.

12. Gurdak J.J., Hanson R.T., Green T.R., Effects of climate variability on groundwater resources of the United States. US Geological Survey Fact Sheet 2009-3074, 4 p.

13. Rivard C., Vigneault H., Piggott A., Larocque M., Anctil F., Groundwater recharge trends in Canada. Can. J. Earth Sci. 46, 2009, 841-854.

14. Toure N.M., Kanec A., Noeld J.F., Turmine V., Nedeff V., Lazare G., Water-poverty relationships in the coastal town of Mbour (Senegal): Relevance of GIS for decision support. International Journal of Applied Earth Observation and Geoinformation, 14, 2012, 33-39. 